\title{
Investigation Microwave Furnace Effects on Mechanical Properties and Fatigue Life of AA 7075-T73 with Dry and Acid Treatments
}

\author{
Sadiq Jaffer Aziz* \\ Ahmed Adnan AL-Qisy** \\ Rafeef Jumaa Salman*** \\ *,**,**Department of Mechanical Engineering/ University of Technology \\ *Email: S-J-aziz@ hotmail.com \\ ** Email: abomrem2004@gmail.com \\ *** Email: Rafef1362@gmail.com
}

(Received 4 June 2017; accepted 31 October 2017)

https://doi.org/10.22153/kej.2018.10.001

\begin{abstract}
Microwave heating is caused by the ability of the materials to absorb microwave energy and convert it to heat. The aim of this study is to know the difference that will occur when heat treating the high strength aluminum alloys AA7075-T73 in a microwave furnace within different mediums (dry and acidic solution) at different times (30 and 60) minutes, on mechanical properties and fatigue life. The experimental results of microwave furnace heat energy showed that there were variations in the mechanical properties (ultimate stress, yielding stress, fatigue strength, fatigue life and hardness) with the variation in mediums and duration times when compared with samples without treatment .The ultimate stress, yielding stress and fatigue strength decreased for all states compared with standard values. With reference to fatigue life, the results showed that the increment in fatigue life occurred for test states of dry 60 minutes in a microwave furnace, which were only $25 \%$. Moreover, the increment in hardness range was reached for test state of acid in 60 minutes which was about $7.3 \%$, and $5 \%$ for dry in 30 minutes and only $3 \%$.
\end{abstract}

Keywords: Aluminum alloy, Fatigue life, Heat treatment, Mechanical properties, Microwave Furnace.

\section{Introduction}

Microwaves had been part of the electromagnetic spectrum with frequencies ranging from $300 \mathrm{MHz}$ to $300 \mathrm{GHz}$ and consistent wavelengths between $1 \mathrm{~m}$ and $1 \mathrm{~mm}$ respectively $[1,2]$. However, $2.45 \mathrm{GHz}$ and $915 \mathrm{MHz}$ were the commonly-using microwave frequencies for study and industrial actions $[3,4]$. Heat generated from within the body by the absorption of Microwave Furnace Heat Energy (MFHE) directly by the body and does not need substantial heating of the environment. Therefore, a temperature gradient exists in both conventional and MFHE as a result of the way heat is transferred/generated in the object [1]. Microwave furnace heat energy processing's are a green manufacturing process, significantly fast and hence tends to be highly economical. MFHE had been effectively and efficiently using for processing of ceramics and composite materials which are else hard to process through conventional processes $[1,6]$, its fine microstructures and improved mechanical properties are observed with reduced processing duration time [6]. When a material absorbs MFHE, heat can be generated inside the material and heating was instantaneous generated with the introduction of power [1,2]. Another advantage of microwave furnace heating was that it could accelerated reaction rates and reduces reaction temperatures by reducing activation energy [2]. Microwave material processing technology had 
been gaining much interest due to the relatively low manufacturing costs, energy and time saving, the fast sintering process, short soaking time, higher energy efficiency, improved product uniformity and high yields [3]. There are number of reports related with microwave oven heating of metals in various fields: Sintering, Joining, Metal glass and composite materials [5]. Also, it used to reduce metal oxides to their metallic forms may product in problems connected with microwave communication with molten metals [2]. In microwave furnace heat processing, MFHE heats the alloy at the varies heat levels, which will might leads to a uniformly bulk heating, conversely in the conventional heating systems, the alloy heated from inner core to the surface which produces thermal stress and/or longer time required for homogenization [1]. The fracture strength, toughness and hardness arrived from microwave furnace energy of treated specimen components were reported to be higher than others conventionally heat-treated application ones [6,7]. A heat-treating process by microwave furnace can be used for a wide application of surface treatments such as carbonating, carburizing, bronzing and chroming [8,9].

In this work, a newer technique including microwave furnace post heat treatment of sample surface were employed. Period microwave furnace was used efficiently to process AA7075T73. The research concentrated on the mechanical properties and estimated fatigue life affected by the microwave furnace energy heat treatment of the alloy used. In this work, the sheet material was heat treated using microwave furnace energy at $2450 \mathrm{MHz}$ and $900 \mathrm{~W}$ and the estimated fatigue life as long as its effect on mechanical properties is discussed in this work in details.

\section{Experimental Work \\ 2.1 Material Selection}

7XXX series aluminum alloys have been widely used as structural materials in aeronautical industries due to their attractive comprehensive properties, such as low density, high strength, ductility, toughness and resistance to fatigue [10], Also it attracting much attention because of their favorable strength-to-weight ratio and corrosion resistance compared to conventional stainless steels[11,12].The $7 \mathrm{xxx}$-series alloys have zinc as their primary alloying agent, with a small amount of magnesium added. Some alloys also contain copper or chromium [13]. It is general known that aluminum alloy 7075-T73 has high strength and relatively a very good resistance for corrosive [12]. The chemical composition of AA 7075-T73 shown in Table 1, the tests were conducted at the COSQC-Baghdad (Central Organization for Standardization and Quality Control) according to the ISQ (Iraqis Specification Quality) 1473/1989 by the device (Spectrometer, ARC. MET 8000, 2009). The standard properties are given with the actual results in Table 2.

Table 1,

Chemical composition of the aluminum alloys [ASTM]

\begin{tabular}{|c|c|c|c|c|c|}
\hline $\begin{array}{l}\text { Compo } \\
\text { nent }\end{array}$ & $\% \mathbf{S i}$ & $\begin{array}{l}\% \\
\mathrm{Fe}\end{array}$ & $\begin{array}{l}\% \\
\mathrm{Cu}\end{array}$ & $\% \mathrm{Mn}$ & $\% \mathrm{Mg}$ \\
\hline $\begin{array}{l}\text { Stand. } \\
\text { ASTM }\end{array}$ & $\leq 0.4$ & $\leq 0.5$ & $\begin{array}{l}1.2- \\
2.0\end{array}$ & $\leq 0.3$ & $2.1-2.9$ \\
\hline Used & 0.28 & 0.26 & 1.51 & 0.21 & 2.24 \\
\hline $\begin{array}{l}\text { Compo } \\
\text { nent }\end{array}$ & $\% \mathrm{Cr}$ & $\begin{array}{l}\% \\
\mathrm{Zn}\end{array}$ & $\% \mathrm{Ti}$ & $\begin{array}{l}\% \\
\text { other }\end{array}$ & $\% \mathrm{Al}$ \\
\hline $\begin{array}{l}\text { Stand. } \\
\text { ASTM }\end{array}$ & $\begin{array}{l}0.18- \\
0.28\end{array}$ & $\begin{array}{l}5.1- \\
6.1\end{array}$ & $\leq 0.2$ & $\leq 0.15$ & Rem. \\
\hline Used & 0.265 & 5.18 & 0.03 & 0.098 & Rem. \\
\hline
\end{tabular}

Table 2,

Mechanical properties of AA 7075-T73 as taken from the SIER and/or COSQC

\begin{tabular}{ll}
\hline Mechanical Properties & $\mathbf{7 0 7 5 - T 7 3}$ \\
\hline Hardness Value Rockwell B & 89.5 \\
Ultimate Tensile Strength & $496 \mathrm{MPa}$ \\
Tensile Yield Strength & $385 \mathrm{MPa}$ \\
Elongation at Break & $18 \%$ \\
Modulus of Elasticity & $76.3 \mathrm{GPa}$ \\
Fatigue Strength & $223 \mathrm{MPa}$ \\
Suface roughness & 0.6 \\
\hline
\end{tabular}

\subsection{Specimen Preparation}

AA7075-T73 plat with thickness (3mm) formed to a standard test specimen (tensile, fatigue life). The sample profile was obtained using a CNC milling machine with a special fixture to achieve specimen geometry accordance with the standard [ASTM E9M]. Sample must be personnel and accurately calibrated as long as the tensile machines and this is very important before applying the test. Preparation the specimen maybe concludes: grinding and polishing the samples. 


\subsection{Process Parameters}

In this work the specimen was mounted into the microwave furnace type (Lifetec Mikrowelle 2450 MHZ,900W) as shown in Fig.1, the specimens were installed in baker filled with 1 liter of acidic mediums (organic vinegar, acidity 4-6 \%). Two-time interval was selected, $30 \mathrm{~min}$. and $60 \mathrm{~min}$. respectively. The reason to selecting such interval time is from formal research [7]. The mean idea is to estimate the effects of thermal energy arrived by the heat weaves of microwaves furnace. Then the samples were left to be cooled slowly inside the microwave furnace. For another test, the samples were placed inside the microwave in dry medium also treated in microwave furnace at different time (30 and 60 $\min )$.

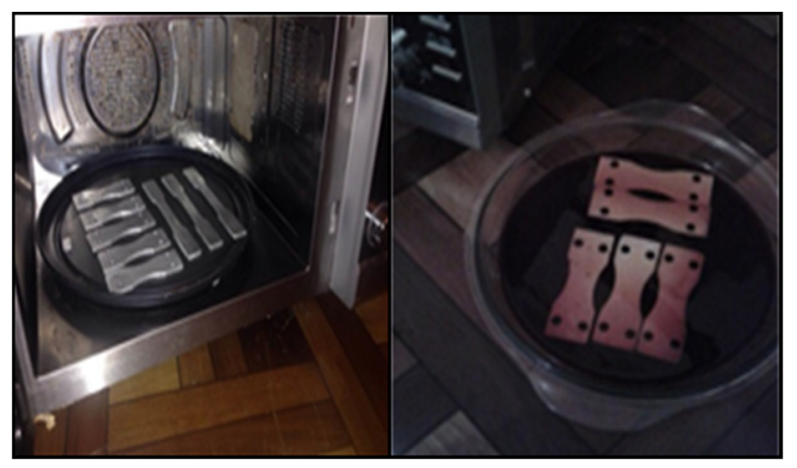

Fig. 1. Microwave Furnace with Sample.

\subsection{Mechanical Testes \\ 2.4.1. Tensile Test [ASTM B557M - 15]}

The tensile test was carried out according to American Society for Testing Material (ASTM) [14]. The geometry and dimensions of the plate tensile samples were shown in Figs. 2 and 3. The tensile test was done using (50KN Tinus Olsen) testing machine. The average value of three tests is recorded and used to draw the stress-strain curve. The selected sample for such tests must conform to exact physical dimensions and it must be free of heat distortion or induced cold working.

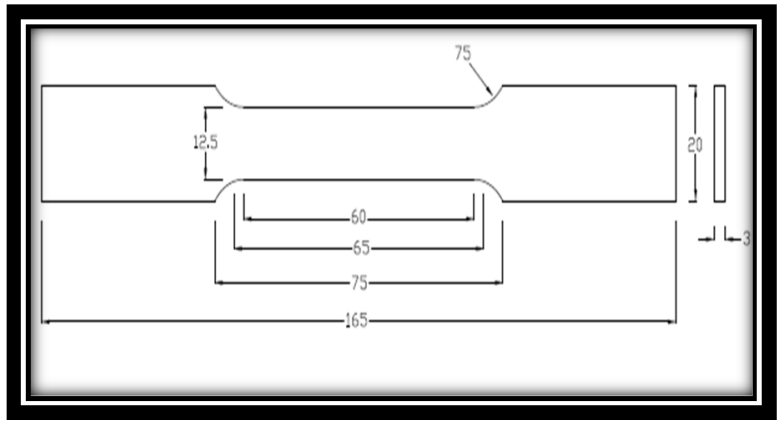

Fig. 2. Standard Tensile Test Sample, all dim. in mm for plane specimen [ASTM E9M].

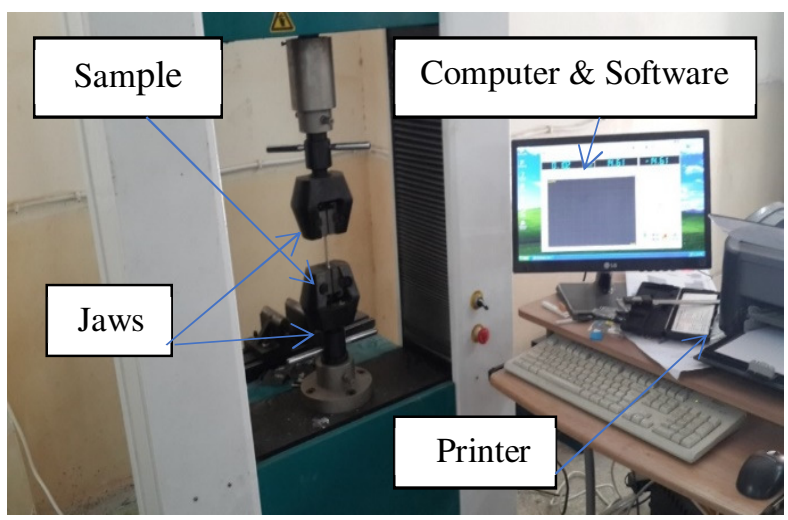

Fig. 3. Tensile Test Machine

\subsubsection{Fatigue life Test [Avery Plane Bending Fatigue Test Machine]}

In this research, A fully reversed reciprocating plane bending fatigue testing machine type AVERY DENISON-7305, was used to carry out the fatigue testing. The tests were undertaken in stress controlled with a stress ratio $\mathrm{R}=-1$ and the cycling rate is $1400 \mathrm{rpm}(\mathrm{f}=23.6 \mathrm{~Hz})$. The machine is provided with a cycle counter. This cycle counter records the number of cycles in multiples of thousands as shown in figs. 4 and 5.

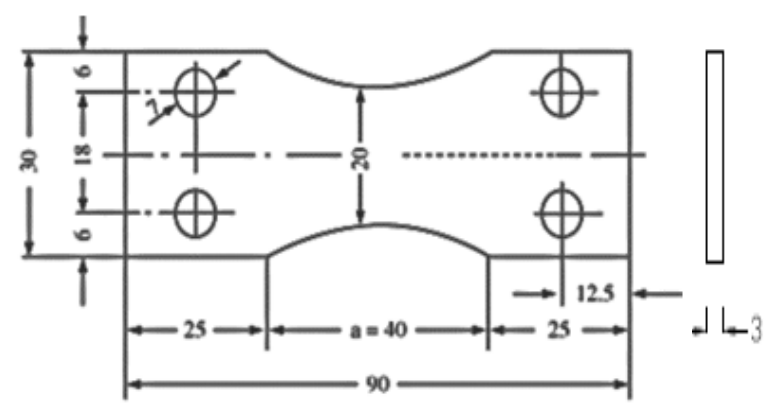

Fig. 4. Standard Fatigue Test Sample with thickness of $3 \mathrm{~mm}$ all dim. in $\mathrm{mm}$ for plane sample [Avery Manual]. 


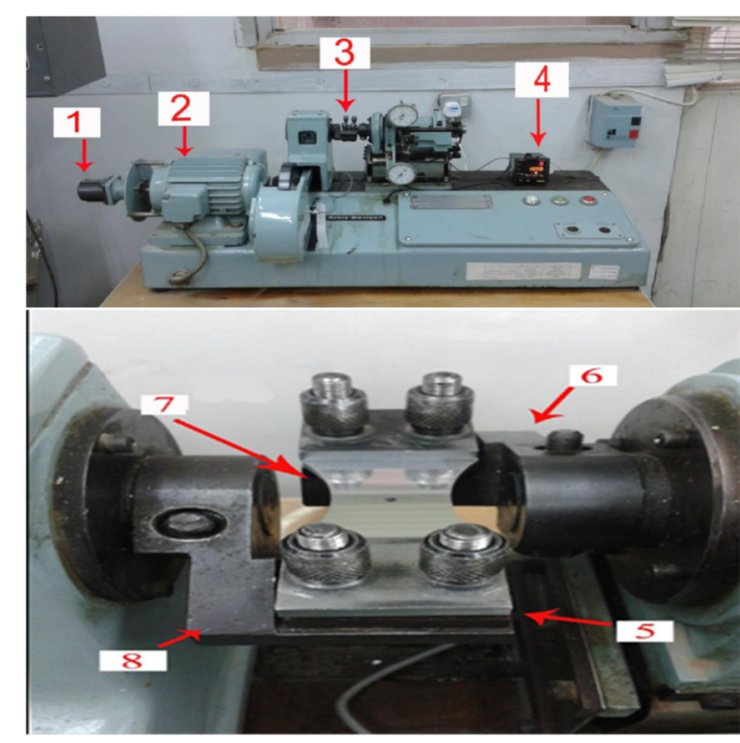

Fig. 5. Plane Bending Fatigue Testing Machine Type Avery Model 7305 1. Mechanical counter 2. Motor 3. Sample fixture 4. Digital counter 5. Clamp 6. Fixed grip 7. The sample 8. Movable

\subsubsection{Hardness Test}

Hardness is the property of a material that enables it to resist plastic deformation, usually by penetration. However, the term hardness may also refer to resistance to bending, abrasion, scratching or cutting. Test [ASTM E110 - 14] was done by (Rockwell Hardness Testing Machine). Fig.6. The Rockwell hardness test method consists of indenting the test material with a diamond cone or hardened steel ball indenter. The samples were polished and mounted on the machine using a dwell time of 15 seconds. The depth of penetration was measured using the Rockwell hardness number was calculated.

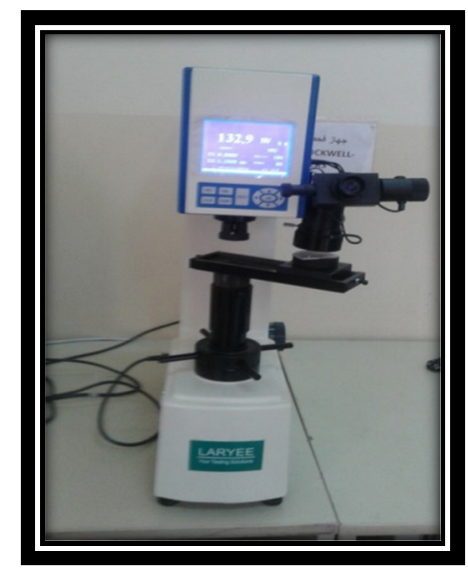

Fig. 6. Rockwell Hardness Testing Machine

\subsubsection{Surface Roughness Tests}

Roughness an important part in computing how a real thing will interaction with its surrounding. In tribology, rough surfaces samples usually wear more quickly and have friction coefficients higher than smooth surfaces. Roughness is often a good predictor of the performance of a mechanical component, since irregularities on the surface may form nucleation sites for cracks or corrosion. On the other hand, roughness may promote adhesion. The test was done by (Pocket surf IV Surface Roughness Testing Machine Fig.7).

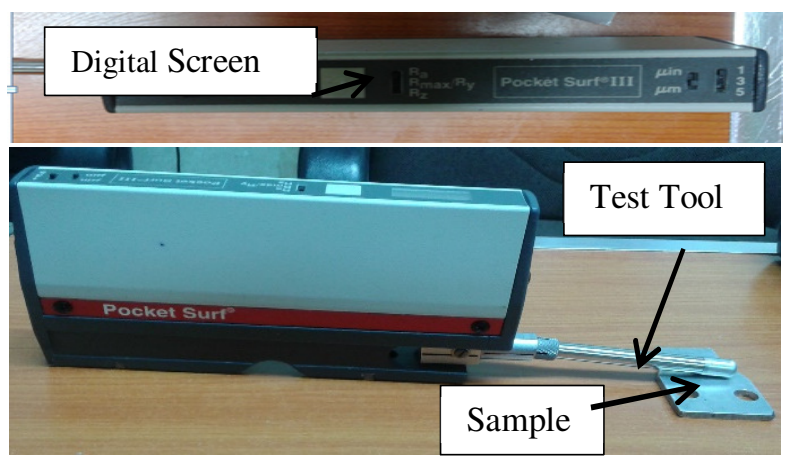

Fig. 7. Pocket surf IV Surface Roughness Testing Machine.

\subsubsection{Microstructure and Surface Topographic Image}

To study the microwave furnace heat energy behavior of AA7075-T73, light microscope images were taken for different regions in the samples surface, where samples prepared with $\left(1 * 1 \mathrm{~cm}^{2}\right)$ selection, mounting, grinding, polishing and etching. The microstructures then characterized by light microscopy Fig.8, after etched by using killer solution $\left(2.5 \mathrm{ml} \mathrm{HNO}_{3}, 1.5\right.$ ml, HCL, $1 \mathrm{ml} \mathrm{HF,} 95 \mathrm{ml} \mathrm{H}_{2} \mathrm{O}$ ).

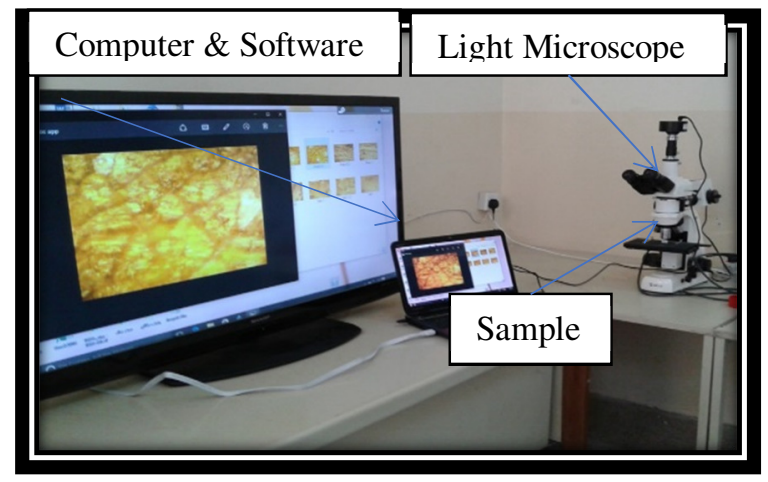

Fig. 8 . Light Microscope Test. 


\section{Experimental Results}

First, the temperature was measured from experimental works, for each medium as shown in Table (3) below. However, Table (4) shows the mechanical properties, of the results that have been calculated after the four tests processes.

Table 3,

Temperatures of mediums

\begin{tabular}{lll}
\hline & \multicolumn{2}{l}{ Temperature $\left({ }^{\circ} \mathbf{C}\right)$} \\
\cline { 2 - 3 } State & $30 \mathrm{~min}$ & $60 \mathrm{~min}$ \\
Dry & 133 & 145 \\
Acid & 70 & 75 \\
\hline
\end{tabular}

1. The ultimate tensile stress, which reduced in all groups compared with standard values. Where maximum reduction of $31.8 \%$ was for dry at testing time $60 \mathrm{~min}$ in a microwave furnace groups, $15 \%$ for dry $30 \mathrm{~min}$ in a microwave furnace. There were less of $2.8 \%$ for test group of acid $60 \mathrm{~min}$. Also, $2 \%$ decrement for dry 30 min group.

2. Also, found that decreasing the yielding with decrements in extension percentage too, where a little effect for tests group of acid 30 and 60 min in microwave furnace of about $2 \%$ and $2.8 \%$ only, while for dry 30 and dry 60 group tests of $15 \%$ and $31.8 \%$ respectively. Fig.9.

3. Elongation at break, the calculated results indicated that the alloys brittleness is increased due to the excessive heat from the microwaves furnace with respect to duration time, which is made some changes in phases of the alloys surfaces leads the gran size of both alloys to decrease figs. 11-13. The extension of these alloys is decreased generally from references due to the same reasons above but the major decrement was for the test group of dry $60 \mathrm{~min}$ in microwave furnace of about $37 \%$ and about $22 \%$ for test group of acid $60 \mathrm{~min}$ in microwave furnace than reference, while there was decrement of about $25 \%$ for test group of dry $30 \mathrm{~min}$ in microwave furnace and only $11 \%$ for the last group all than its references.

4. It is also noticed that, for the fatigue strength test group of dry $60 \mathrm{~min}$ in microwave furnace was decreased its value of about $31.8 \%$ lower than references, while for test group of dry 30 $\min$ in microwave furnace there was decrement of about $15 \%$. But in acid 30 and $60 \mathrm{~min}$ in middle test shows very little effect $2 \%$ and $2.8 \%$ respectively, decrement percentage.

5. There was not a great noticed change in the modulus of elasticity for all tests groups

6. Hardness, it has been noticed that the higher value was for test group of acid60 $\mathrm{min}$ in microwave furnace with increment of about $7.3 \%$ and $5 \%$ for dry 30 from standard without treatment samples, while the decrement in hardness were for dry 60 only about $8.4 \%$ and $4 \%$ for acid 30 Table (4).

7. Surface roughness, noticed that when time increasing the temperature increasing and the surface roughness increase. The majority effects were at (60 and 30) min with acidic mediums (133\%and 66\%) respectively, that because of corrosion occurred on the surface of the sample led to initiation pits which increase surface roughness with increase duration time as shown in fig.12, $40 \%$ increment was occurred for dry 60 min group figure. showed that, while the effect was occurring at dry 30 min tests only about $21.7 \%$. 
Table 4,

Mechanical Properties of AA 7075-T73 have been calculated of the four groups.

\begin{tabular}{llllll}
\hline State & \multicolumn{3}{c}{ Dry } & \multicolumn{2}{c}{ Acid } \\
& Ref. & 30min & 60min & 30min & 60min \\
Property & & & & & \\
\hline Ultimate Tensile Stress value MPa $\left(\sigma_{\text {ult }}\right)$ & 496 & 425 & 338 & 485 & 482 \\
Tensile Yield Stress value MPa $\left(\sigma_{\mathrm{y}}\right)$ & 385 & 310 & 207 & 380 & 365 \\
Extension \% & 18 & 13.6 & 11.2 & 16 & 14 \\
Fatigue Strength value MPa $\left(\mathrm{S}_{\mathrm{f}}\right)$ & 223 & 191.3 & 151.2 & 218.3 & 216.9 \\
Modulus of Elasticity value $(\mathrm{E}) \mathrm{GPa}$ & 76.3 & 77.3 & 75.1 & 75.75 & 76 \\
Hardness Rockwell B Value & 89.5 & 94 & 82 & 86 & 96 \\
Surface roughness value $\mathrm{Ra}(\mu \mathrm{m})$ & 0.6 & 0.73 & 0.84 & 0.997 & 1.4 \\
\hline
\end{tabular}

Table 5,

Mathematically represent of Basquin equation (amplitude stress) бa MPa

\begin{tabular}{lll}
\hline State & & $\sigma_{a}=\sigma_{f} \cdot N_{f}^{-b}$ \\
Reference & & $\sigma_{a}=\sigma_{f} \cdot N_{f}^{-0.079}$ \\
& & $\sigma_{a}=\sigma_{f} \cdot N_{f}^{-0.1068}$ \\
Dry & $30 \mathrm{~min}$ & $\sigma_{a}=\sigma_{f} \cdot N_{f}^{-0.0713}$ \\
& $60 \mathrm{~min}$ & $\sigma_{a}=\sigma_{f} \cdot N_{f}^{-0.1157}$ \\
Acid & $30 \mathrm{~min}$ & $\sigma_{a}=\sigma_{f} \cdot N_{f}^{-0.105}$ \\
\hline
\end{tabular}

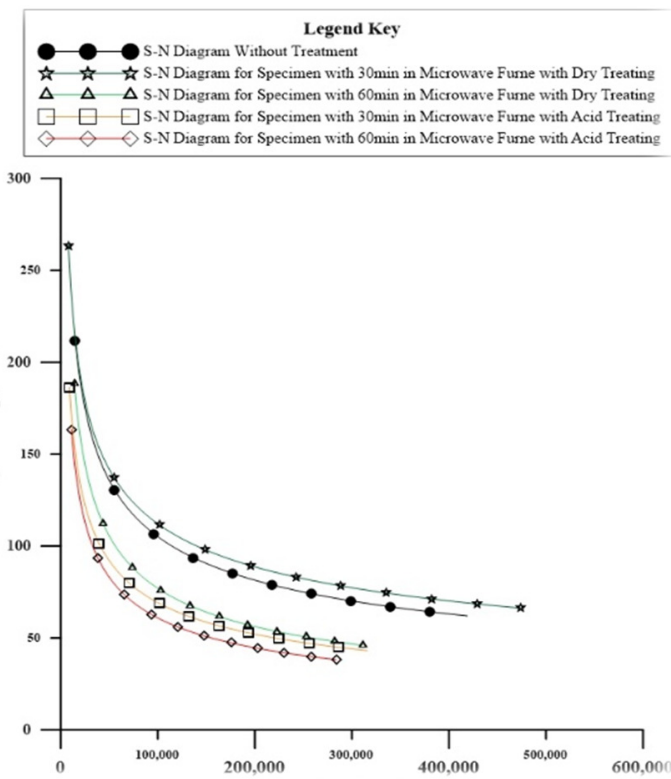

Fig. 9. Stress-Strain chart for tensile test.

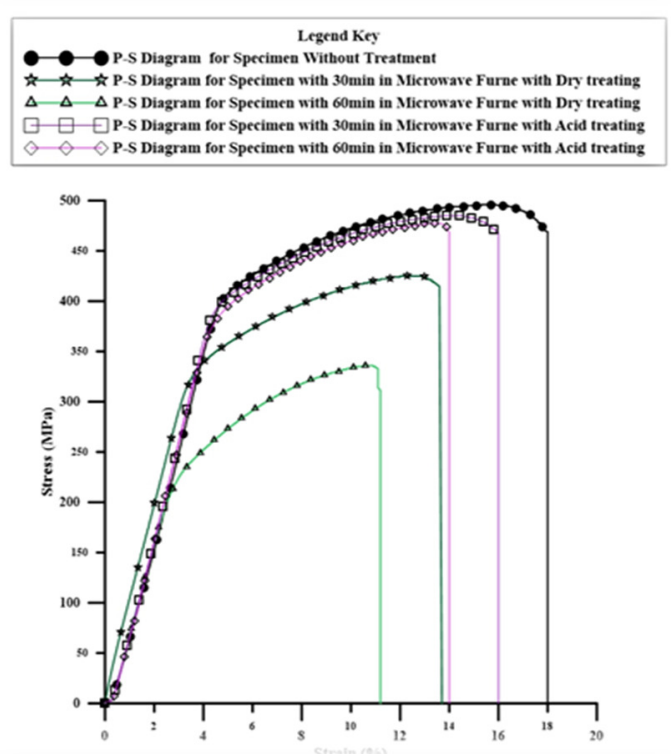

Fig. 10. $\mathrm{S}-\mathrm{N}$ curves for all the fatigue tests samples. 

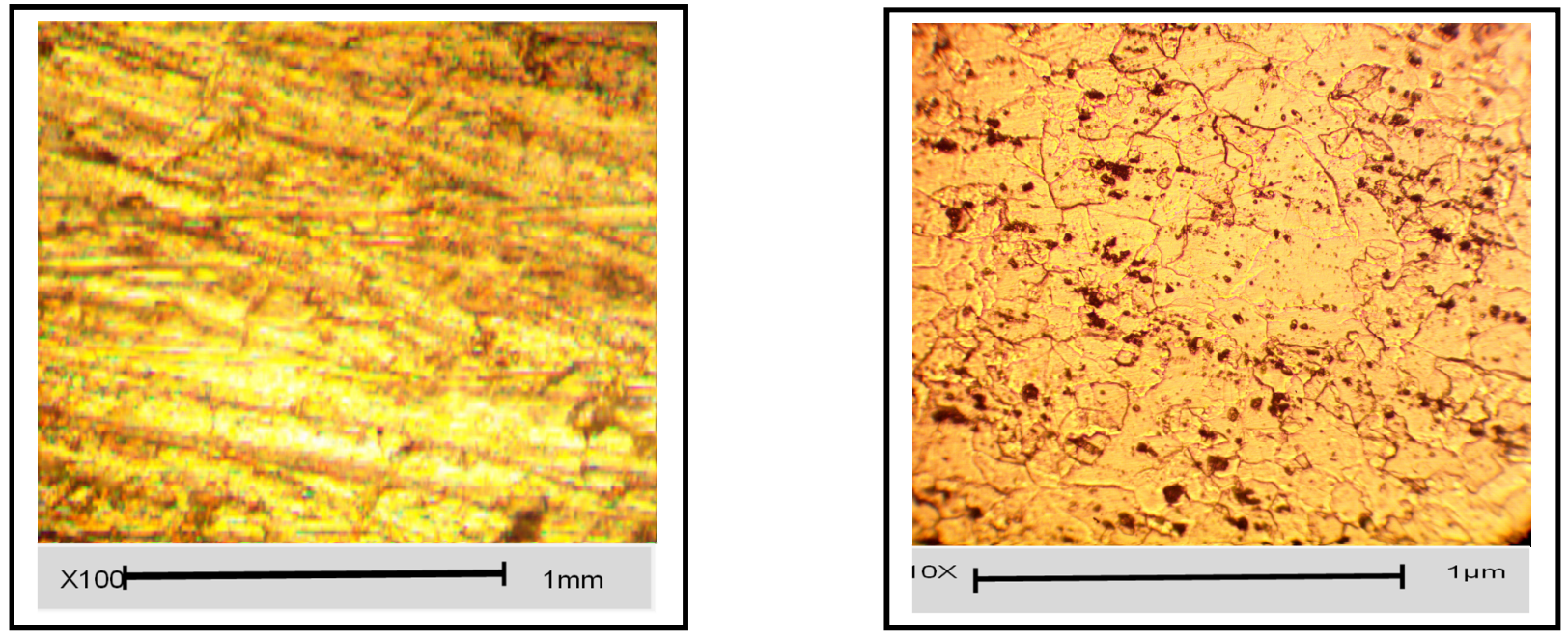

Fig. 11. Surface topographic and Microstructure of reference sample of AA 7075-T73
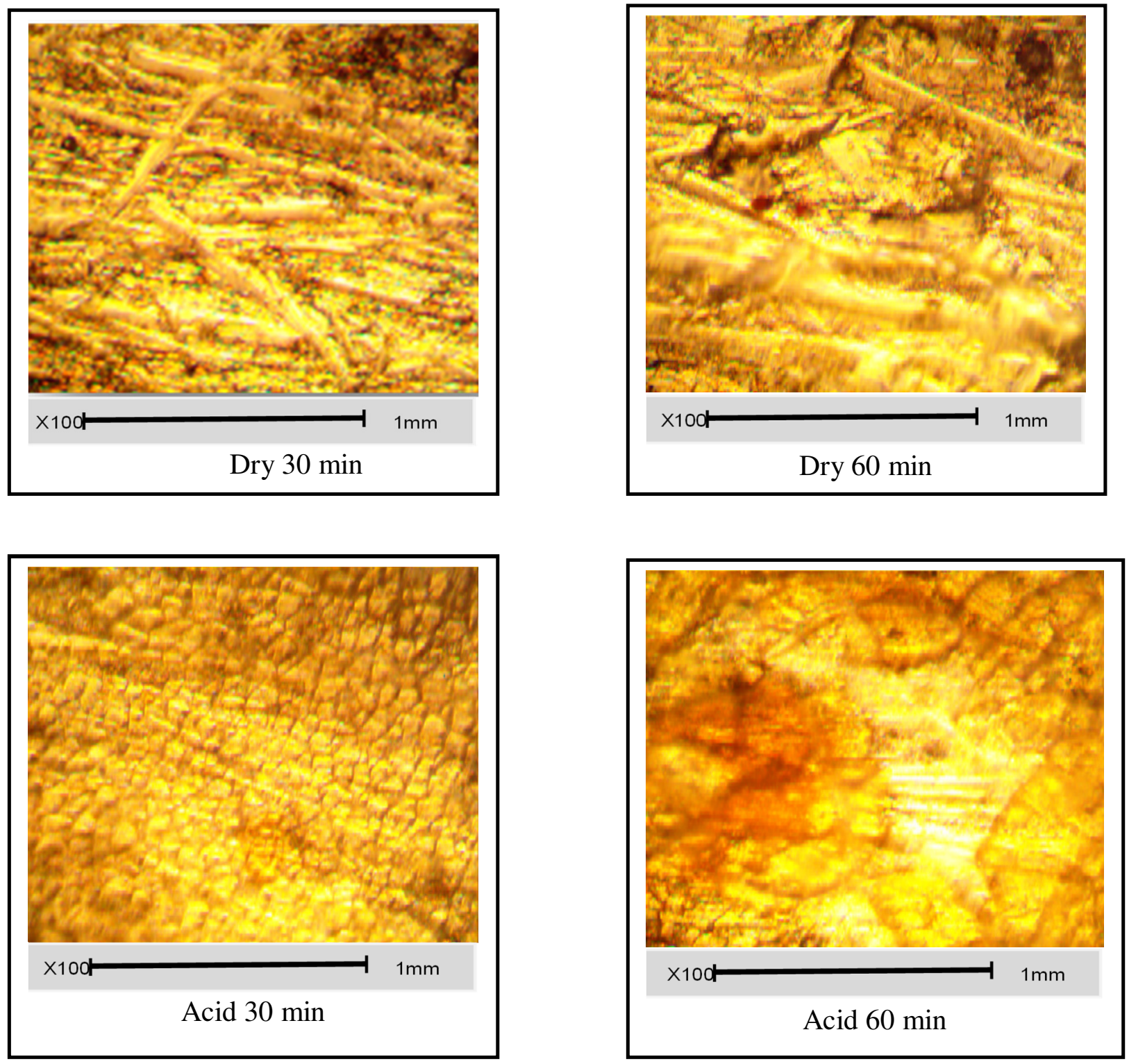

Fig. 12. Surface topography Image for dry and acid mediums (100X). 

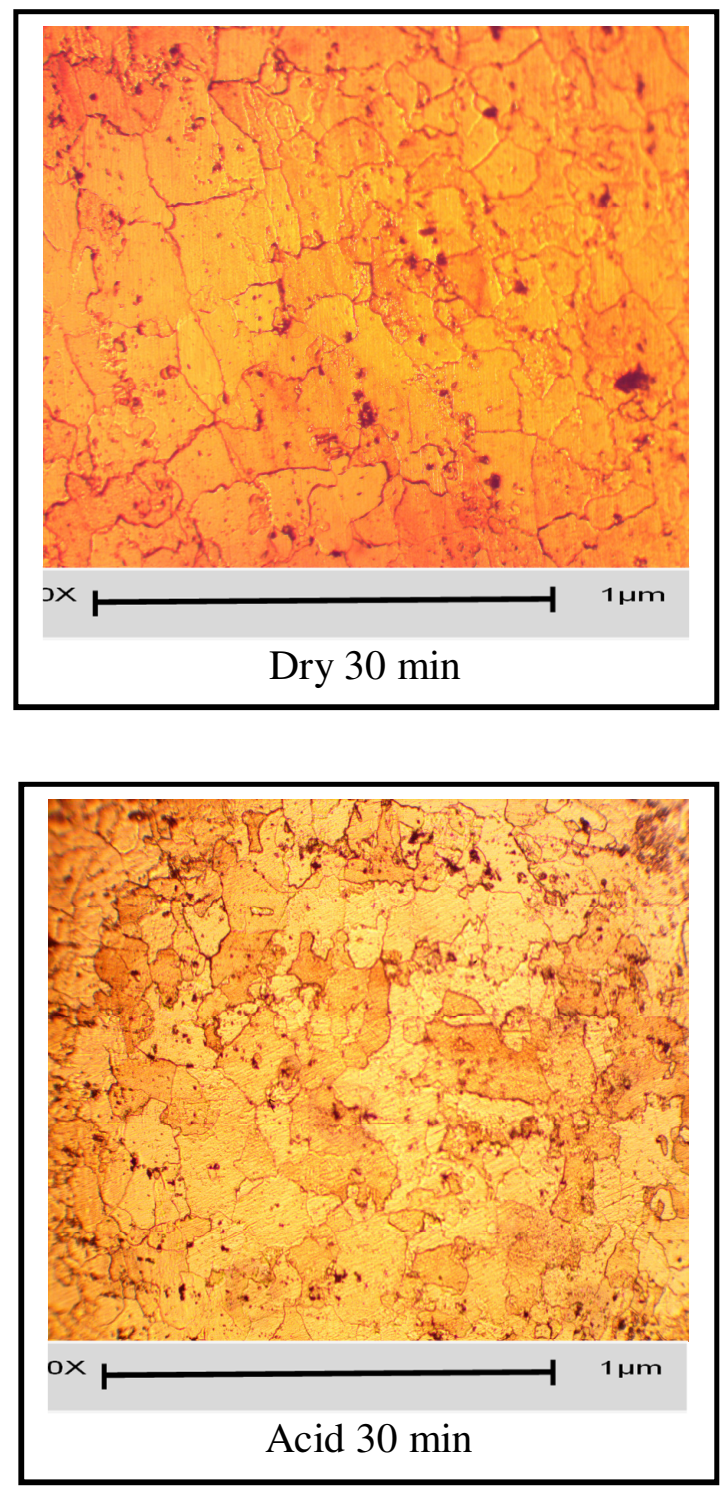
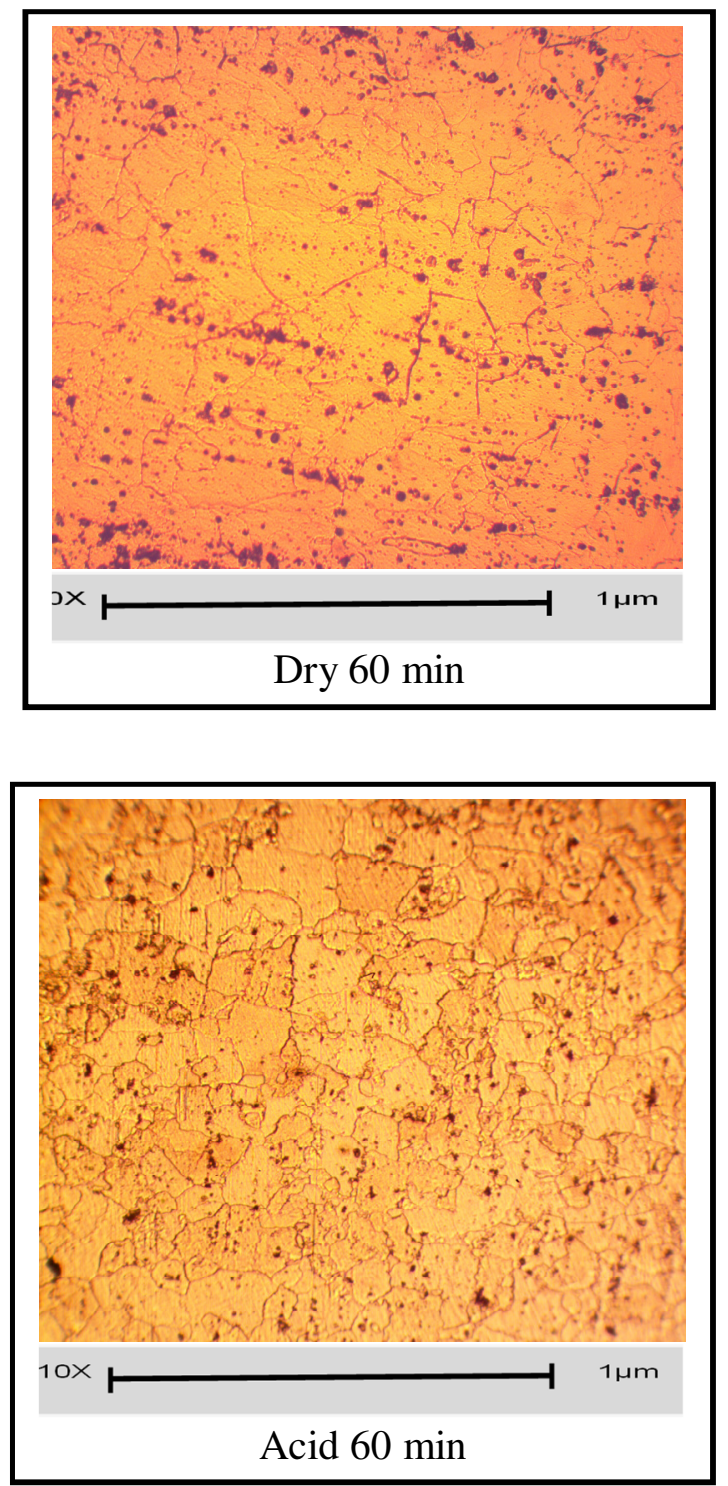

Fig. 13. Microstructure image for dry and acid mediums (10X).

8. Fatigue life, a high cyclic fatigue tests were used at amplitude stress $100 \mathrm{MPa}$ the major increment in fatigue life was for test group of dry with $60 \mathrm{~min}$ in microwave furnace $25 \%$ compared with its original life and the general equation form of life using (Basquin equation, $\sigma_{a}=$ $\left.\sigma_{f} N_{f}^{-b}\right),[15]$. Table 5. The acidic percentage in acidic medium led to corrosion in the surface and occurrence of pits on it. These pits are the places for the initiation of cracks, so the higher surface roughness causing increment in crake propagation, therefore decreasing the fatigue life. Where for a test group of acid $60 \mathrm{~min}$ the decrement was about $75 \%, 62.5 \%$ for acid $30 \mathrm{~min}$ group, for dry $30 \mathrm{~min}$ in a microwave furnace group was only 50\% reduction percentage. Fig.10.
9. For microstructure, it was noticed that when illustrate the microstructures of the specimen surfaces with and without microwaves furnace treating, its clearly notice that changing the treating medium will leads essentially to change the microstructures of the specimen's surfaces treated with microwaves furnace at different medium. The effects clearly noticed for $60 \mathrm{~min}$ in acid medium, more than for the other medium effect on the microstructure. Figs.11and 13.

\section{Discussion and Conclusion}

1. In this work it has been found that a certain microwaves furnace duration time could made major effects on one or more of the 
mechanical properties including fatigue life, ultimate stresses and yielding stress for the alloys used.

2. For ultimate stress and yielding decrement, the reason of this phenomenon is that the heat temperature creates from energy arrived from microwave furnace hardened the surface of the alloy from inside to outside. So, when the surface cooled, the grin cells size became smaller compared with the internal grin cells which still at its original size because it cooled slower, so when sample had been tested for tensile test and check the result it was found that a decrement occurs. Figs 11-13 shows the effects of dry and acidic mediums at the surfaces of the alloys.

3. For elongation at break, the determined results showed that the alloys brittleness is raised due to the excessive heat from the microwaves furnace with deference to duration time, which make some changes in nature of the alloy surface leads the gran size of both alloys to be changed figs 11 and 13. The extension of these alloys is reduced generally from references due to these reasons above.

4. The fatigue strength is an indication of both ultimate stress, yielding and elongation, and since all were decreased essentially that will leads to decrease its value.

5. The acidic contains in acid medium led to corrosion in the surface and occurrence of pits on it, these pits are the place for the initiation of cracks and the higher hardness of the surface and high surface roughness led to increasing in crake propagation so decrease the fatigue life, figs 12 and 13.

6. Using a microwaves furnace might be useful if knowing its effects on the mechanical properties because that will shorten both the time and cost of changing these properties into certain levels by only using suitable method and/or duration time and amount of heat.

7. The great benefits of availability of microwaves furnace in industrial application was found that these microwaves furnace changes it's mechanical properties in deferent levels than that for classical heat treatment methods, this change depends upon the parameters applied from changing the time duration to heat amount and different conditions, the amount of mechanical properties that changed even if it was not huge in some properties but clearly noticed especially if we know that this application is safe and cheap with respect to other applications which gives this processes privilege as the other applications doesn't optimize the material beater, so for those how need quick not expensive easily handled safe and with acceptable change of mechanical properties, the microwaves furnace is the best choice for them.

8. The study clearly shows that there is no harm of using aluminum alloy in microwaves furnace.

\section{References}

[1] Wai Leong Eugene Wong, and Manoj Gupta" Using Microwave Energy to Synthesize Light Weight/Energy Saving Magnesium Based Materials" Technologies, 3, 1-18, 2015

[2] Xiang Sun, Jiann-Yang Hwang*, Xiaodi Huang, Bowen Li, Shangzhao Shi" Effects of Microwave on Molten Metals with Low Melting Temperatures" Journal of Minerals \& Materials Characterization \& Engineering, Vol. 4, No. 2, pp 107-112, 2005

[3] Penchal Reddy Matli, Rana Abdul Shakoor, Adel Mohamed Amer Mohamed and Manoj Gupta " Microwave Rapid Sintering of AlMetal Matrix Composites: A Review on the Effect of Reinforcements, Microstructure and Mechanical Properties" MDPI Metals 2016, 6, 143; doi:10.3390/met6070143

[4] Michael Vollmer" Physics of the microwave oven" Germany, Physical Education 39 (1).2004.

[5] Noboru Yoshikawa" Fundamentals and Applications of Microwave Heating of Metals" Japan, Journal of Microwave Power and Electromagnetic Energy, 44 (1), pp. 4-13, 2010.

[6] Manoj Gupta and Wong Wai Leong, Eugene "Microwaves and Metals "John Wiley \& Sons (Asia) Pte Ltd, 2 Clementi Loop, 02-01, 2007.

[7] Ahmed Adnan AL-Qaisy, Eng. Sameh Fareed Hasan, Najmuldeen Yousif Mahmood" Study 
the Effects of Microwave Furnace Heat on The Mechanical Properties and Estimated Fatigue life of AA 2024-T3" Journal of Engineering, No.10, Vol.23, 2017

[8] Satnam Singh, Dheeraj Gupta, Vivek Jain and Apurbba K. Sharma" Microwave Processing of Materials and Applications in Manufacturing Industries" Taylor \& Francis Group Materials and Manufacturing Processes, 30: 1-29, 2015.

[9] D. Loganathana, A. Gnanavelbabub, K. Rajkumar and R. Ramadoss" Effect of Microwave Heat Treatment on Mechanical Properties of AA6061 Sheet Metal"Science Direct, Procedia Engineering 97,1692 $1697,2014$.

[10] LI Jin-feng, PENG Zhuo-wei, LI Chao-xing, JIA Zhi-qiang, CHEN Wen-jing and ZHENG Zi-qiao" Mechanical properties, corrosion behaviors and microstructures of 7075 aluminum alloy with various aging treatments" Transaction of nonferrous metals society of china $18,755-762.2008$.
[11] Zabih-Alah Khansha1, Mohammad R. Saeri2 and Sasan Otroj" Study of Stress Corrosion Cracking of AA7075-T6 Aluminum Alloy by Chromate Coatings in Aerial Industry" Indian Journal of Fundamental and Applied Life Sciences ISSN: 2231- 6345 (Online). 2015.

[12] Fatima Ali Hussain" Fatigue of 7075T6 Al alloy under different conditions of corrosion" A thesis of Master Al-Mustansiriyah University, Materials Engineering Department. 2016.

[13] Adeyemi Dayo Isadare, Bolaji Aremo, Mosobalaje Oyebamiji Adeoye, Oluyemi John Olawale, Moshood Dehinde Shittu" Effect of Heat Treatment on Some Mechanical Properties of 7075 Aluminum Alloy" Materials Research.; 16(1): 190-194, 2013.

[14] ASTM, Standard Specification for Aluminum and Aluminum-Alloy Sheet and Plate, USA, 2012.

[15] F. C. Campbell" Elements of Metallurgy and Engineering Alloys" American Society for Metals (ASM), p 243-264, 2008 


\title{
التحقى من تأثير افران الموجات الاقيقة على الخواص الميكانيكية وعمر الكلل AA 7075-T73

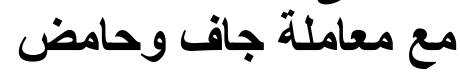

\author{
رف***ن رمعة سلمان

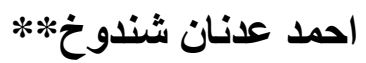 \\ صادق جعزر عزيز

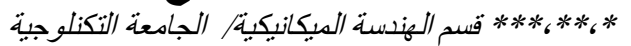 \\ S-J-aziz@ hotmail.com البريد الالكتروني: \\ abomrem2004@gmail.com البريد الالكتروني: الاكترون:**** \\ Rafef1362@gmail.com البريد الالكتروني:**** البرني:
}

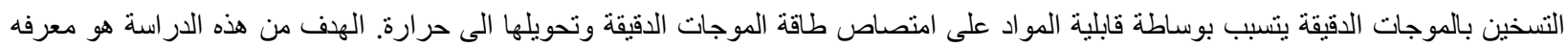

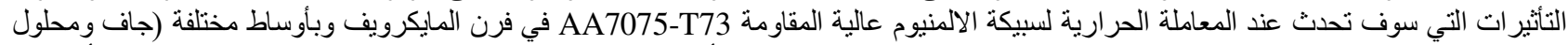

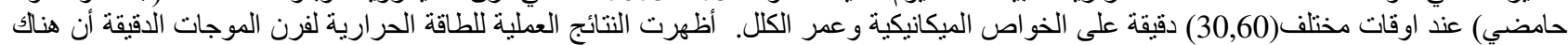

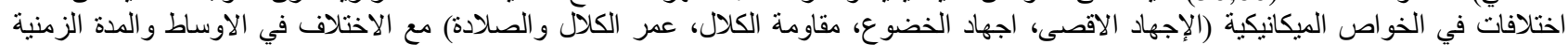

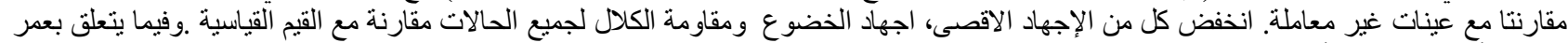

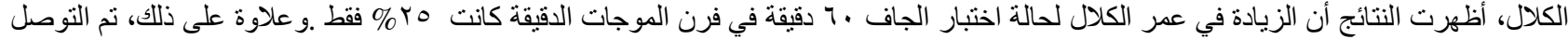

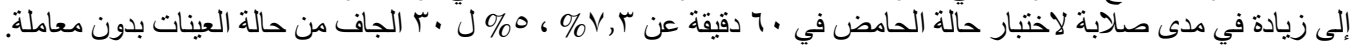

